\title{
The Influence of Surface Sediment Presence on Observed Passive Microwave Brightness Temperatures of First-Year Sea Ice during the Summer Melt Period
}

\author{
Madison L. Harasyn, Dustin Isleifson \& David G. Barber
}

To cite this article: Madison L. Harasyn, Dustin Isleifson \& David G. Barber (2019) The Influence of Surface Sediment Presence on Observed Passive Microwave Brightness Temperatures of First-Year Sea Ice during the Summer Melt Period, Canadian Journal of Remote Sensing, 45:3-4, 333-349, DOI: $10.1080 / 07038992.2019 .1625759$

To link to this article: https://doi.org/10.1080/07038992.2019.1625759

\section{Published online: 17 Jun 2019.}

Submit your article to this journal $\pi$

ЏIII Article views: 116

Q View related articles ¿ك

View Crossmark data $₫$ 


\title{
The Influence of Surface Sediment Presence on Observed Passive Microwave Brightness Temperatures of First-Year Sea Ice during the Summer Melt Period
}

\author{
Madison L. Harasyn ${ }^{a}$, Dustin Isleifson ${ }^{\mathrm{a}, \mathrm{b}}$, and David G. Barber ${ }^{\mathrm{a}}$ \\ ${ }^{a}$ Centre for Earth Observation Science, Department of Environment and Geography, University of Manitoba, Winnipeg, Canada; \\ ${ }^{b}$ Department of Electrical and Computer Engineering, University of Manitoba, Winnipeg, Canada
}

\begin{abstract}
Knowledge on the influence of sea ice sediment on passive microwave brightness temperatures $\left(T_{B}\right)$ is currently limited, leading to potential inaccuracies in derived sea ice concentrations where this ice exists. We propose that sediment may influence $T_{B}$ in two ways: (i) by altering the surface dielectrics, or (ii) by generating differential melt rates across the ice surface, increasing surface roughness. This study will examine the second proposed hypothesis through a multi-platform analysis, combining in-situ passive microwave and unmanned aerial vehicle (UAV) data. UAV image analysis shows a negative relationship between surface elevation and sediment concentration. Comparing this with observed $T_{B}$ shows that horizontally polarized emissions are the most sensitive to rougher ice surfaces with 19 and $37 \mathrm{GHz} \mathrm{T}_{\mathrm{B}}$ decreasing rapidly with increased incidence angle. At a $55^{\circ}$ incidence angle, $89 \mathrm{GHz}$ offers the greatest potential for discriminating sea ice surfaces influenced by sediment presence, as $T_{B}$ are greater in both polarizations in comparison with non-sediment-laden ice. Results from this research provide evidence for a relationship between sea ice surface sediment and passive microwave signature, meriting future research in this field.
\end{abstract}

\section{RÉSUMÉ}

Les connaissances de l'influence de la présence de sédiments à la surface de la glace de mer sur le rayonnement thermique des micro-ondes passives $\left(T_{B}\right)$ sont présentement limitées. Cela mène à des inexactitudes dans le calcul des concentrations de glace de mer où I'on retrouve ce type de glace. Nous proposons que les sédiments influencent $T_{B}$ de deux manières: (i) en altérant les propriétés diélectriques de la surface ou encore; (ii) en affectant le taux de fonte sur l'ensemble de la surface de la glace de mer, augmentant la rugosité de la surface. Cette étude examinera la seconde hypothèse par l'entremise d'une analyse mixte, soit en combinant des données de micro-ondes passives in situ ainsi que des données d'aéronef sans pilote. L'analyse des images de drone démontre une relation négative entre l'élévation de la surface et la concentration de sédiments. La comparaison de ces images avec les valeurs de $T_{B}$ observées démontre que les émissions polarisées horizontalement sont les plus sensibles aux changements de rugosité de la surface, avec les $T_{B}$ de 19 et $37 \mathrm{GHz}$ diminuant rapidement avec une réduction de l'angle d'incidence. À un angle d'incidence de $55^{\circ}, 89 \mathrm{GHz}$ offre le meilleur potentiel de différenciation de la glace chargée de sédiments, car les $\mathrm{T}_{B}$ sont supérieurs dans les polarisations verticales et horizontales que pour la glace ne présentant pas de sédiment à sa surface. Les résultats de cette étude démontrent qu'il y a une relation entre la présence de sédiments à la surface de la glace de mer et sa signature dans les micro-ondes passives, ce qui mérite d'être étudié davantage.

\section{ARTICLE HISTORY}

Received 27 November 2018

Accepted 27 May 2019

\section{Introduction}

Sea ice concentrations (SIC) have been mapped since the 1970s through the use of passive microwave retrieval algorithms, which utilize the contrast in emissivity between open ocean and sea ice to derive concentration values (Markus and Cavalieri 2000; Lavergne et al. 2019). Intercalibration between consecutive passive microwave sensors has allowed for the generation of a near-continuous SIC record (e.g., NOAA/NSIDC Climate Data Record: Peng et al. 2013; EUMETSAT's OSI-SAF: Tonboe et al. 2016) used in climate and earth process modeling (Gentemann et al. 2010; Peng et al. 2013; Lavergne et al. 2019). Ice concentration algorithms estimate concentration and 
extent adequately on a hemisphere-wide scale; however, these algorithms can disagree on a fine scale under the influence of localized differences in sea ice thermodynamics, particularly during the melt period (Ivanova et al. 2015; Comiso, Meier, and Gersten, 2017).

To calculate SIC on a global scale, sea ice algorithms make large-scale assumptions of sea ice properties rendering inaccurate concentration estimates on a regional scale. For example, the NASA Team algorithm uses tie points to calculate ice concentration from brightness temperature $\left(\mathrm{T}_{B}\right)$; however, these tie points are generalized for the entire Arctic, leading to low precision regionally (Andersen et al. 2007). Small-scale studies of how these local variances (e.g., ponding, ridging) influence the emission properties of sea ice have been completed, leading to the use of dynamic tie points in SIC algorithms which allow for the algorithm to reflect changes in sea ice thermodynamics (Lavergne et al. 2019). Such studies have not been conducted to assess the influence of sediment presence on SIC retrievals.

The distribution of sediment-laden ice in the Arctic is regionally specific, being limited in extent by a combination of factors necessary for formation. Sediment can become entrained in sea ice during initial freezing in sediment-laden waters, or from anchor ice rafting in shallow waters (Ledley and Pfirman 1997). Conditions required for the inclusion of sediment during freezing include strong, freezing winds, turbulence, and shallow waters (Reimnitz et al. 1993). Anchor rafting occurs in areas of underwater ice formation and where waters are shallow and turbid, allowing for ice crystals to be carried to the underlying substrate and begin growing an ice-bonded crust (Reimnitz et al. 1987). This often occurs in areas where sediments are saturated with water of the same or lower salinity than the water column, such as areas of riverine input into a marine setting (Reimnitz et al. 1987). After a crust is formed, anchor ice can detach and rise to the surface, serving as the surface layer for new ice formation (Reimnitz et al. 1987). Both mechanisms of sediment entrainment require waters less than $50 \mathrm{~m}$ deep (Reimnitz et al. 1993), restricting the generation of sediment-laden ice in the Arctic to shallow coastal regions. Sediment-laden sea ice has been observed in the Beaufort and Chukchi Seas (Reimnitz et al. 1993; Tucker et al. 1999) as well as in Foxe Basin (Campbell and Collin 1958), originating from a coastal source and being transported by currents off shore.
Conditions for sediment-laden sea ice generation are met in the Canadian Hudson Bay coastal area where turbidity is generated from riverine input, coastal depths are shallow, and weather conditions can be extreme (Hochheim and Barber 2014). Hudson Bay experiences a complete freeze/thaw cycle every year, meaning ice in the Bay is completely first year (Gagnon and Gough 2005; Hochheim and Barber 2014). Spring melt begins late May to early June, with the Bay becoming completely ice-free in early August (Andrews, Babb, and Barber 2017). During the melt period, liquid water begins to persist on the ice surface as snow and ice melt due to increasing atmospheric temperatures and solar irradiance (Carsey 1985). This water can collect at the snow-ice interface or in local depressions across the ice, forming melt ponds (Grenfell and Lohanick 1985). Melt-water accumulation on the ice surface masks emissions from the underlying ice (Onstott et al. 1987), rendering ponded sea ice to have an emission pattern resembling highly fragmented ice, and as a result generating an overall decrease in sea ice concentration estimates (Ivanova et al. 2015).

Hudson Bay is relatively shallow ( $150 \mathrm{~m}$ mean depth), and is surrounded by highly shallow coastal shelves (Hochheim and Barber 2014). Riverine input into the Bay is high, with a total discharge of $888 \mathrm{~km}^{3}$ year $^{-1}$ of riverine water flowing into Hudson Bay and Hudson Strait (Déry et al. 2005). The Hudson Bay lowlands are comprised of water-saturated soils, generated from the melt of the Laurentide ice sheet (Abraham and Keddy 2005). The combination of shallow waters and riverine input permits sediment to become entrained in growing sea ice due to suspension freezing during initial ice formation or anchor ice rafting after ice formation (Ledley and Pfirman 1997).

To the authors' knowledge, no previous research has been conducted to determine the impact of surface sediment on the passive microwave signature of sea ice. Current research on the passive microwave signature of sea ice assumes neglects to include sediment-laden sea ice, or concludes that the impact of sediment is negligible due to low sediment concentration (Lohanick and Grenfell 1986). As a result, the impact of sea ice surface sediment presence on passive microwave signature must be hypothesized based on the interaction between sediments, sea ice thermodynamic properties, and electromagnetic emission.

It is proposed that sediment on the sea ice surface can influence the passive microwave signature in two ways: (i) sediment can directly alter the emissivity of 
the ice surface by having different dielectric properties from snow/ice, or (ii) sediment can indirectly influence the melting rate of the ice surface, increasing surface wetness and roughness (relative to non-sediment-laden ice nearby), in turn affecting microwave emission. In previous research, sea ice surface sediment has been described to influence the surface emissivity similar to snow grains (Lohanick and Grenfell 1986) due to the similarity in dielectrics at the microwave frequency (Ulaby and Long 2014). Uncertainties remain in our understanding of how sediment on sea ice affects the rate of ice melt and by extension the small-scale (i.e., centimeter-scale) ice surface roughness.

Sensor incidence angle with respect to the sea ice surface influences the magnitude of measured passive microwave $\mathrm{T}_{B}$ (Ulaby and Long 2014). With increased incidence angle, the emissivity of snow-free and snowcovered first-year sea ice decreases for horizontally polarized emissions, and increases for vertically polarized emissions (Stroeve et al. 2006; Grenfell and Comiso 1986). The incidence angle of measurement can be altered in one of two ways: (i) the angle of the sensor relative to the ground can be changed, or (ii) the angle of the measured surface can be changed relative to the sensor due to surface topography, known as the effective incidence angle. Sea ice surface roughness affects the radiometric signature of the ice through altering the effective incidence angle. The spatial scale of the roughness (Grenfell and Comiso 1986; Hong 2010) and the orientation of surface features (Stroeve et al. 2006) can have a profound influence on radiometric measurements, influencing the magnitude of emission at different frequencies and polarizations. Sea ice surface roughness can be generated by ice ridging, rafting, or by surface melt and refreeze processes during the summer melt period.

Sediment presence on the sea ice surface significantly decreases the integrated albedo of the surface, increasing the total shortwave energy absorbed at the surface (Light et al. 1998). Increased absorbed solar energy can therefore lead to increased ice surface melt rates. We can then hypothesize that melt rate is related to sediment concentration, with higher melt rates being generated from higher sediment concentrations. Based on this hypothesis, an uneven distribution of sediment across the ice surface would generate increased ice surface roughness, with the ice surface experiencing different melt rates spatially.

Unmanned aerial vehicles (UAV) have become increasingly popular for scientific applications, due to their ability to collect high-resolution remote sensing data at site-specific scales. UAVs serve as a platform to carry micro-remote sensing sensors such as optical, multispectral, and LiDAR. High-resolution orthomosaics and digital elevation models can be generated from a set of UAV images over a feature, allowing for in-depth surface analyses. Application of UAV data collection in the Arctic is limited by the harsh climate and limited GPS signal, making Arctic UAV research an emerging field (e.g., Ryan et al. 2015; Castro et al. 2017; Bernard et al. 2017).

This research aims to determine how sea ice surface sediment influences sea ice surface roughness through increased surface melt, and in turn the passive microwave signature of ice. This will be tested using a multisensor approach, combining in-situ passive microwave data and UAV image products. We have investigated the following research questions: (i) does a high surface sediment concentration correspond to increased surface roughness, and (ii) how does the in-situ passive microwave signature change with increased surface roughness generated from surface melt? This paper is structured into two sections: (i) comparing sea ice surface elevation to sediment concentration using a single survey site, and (ii) comparing in-situ $T_{B}$ across multiple surveys with similar thermophysical properties in relation to sea ice surface roughness and progression of surface melt.

Understanding the influence of surface sediments on passive microwave $T_{B}$ is vital for accurate sea ice mapping in sediment-laden areas. Despite the limited extent of sediment-laden ice generation in the Arctic, this ice is located in coastal regions which are areas of importance for other research fields such as nutrient mapping, costal erosion research or the development of sediment budgets (Eicken et al. 2005; Nomura et al. 2010; Wegner et al. 2017). These areas of research are likely to become of increasing importance in the future, as Arctic systems are currently undergoing rapid change as a result of our changing climate (Gagnon and Gough 2005). Therefore, by being able to better monitor sea ice in sediment-laden areas, accurate data can be provided for the monitoring and predictive modeling of attendant processes.

\section{Materials and methods}

\section{Field methods}

\section{Survey site}

Data were collected from June 8 to June 23, 2018 onboard the Canadian Research icebreaker CCGS Amundsen, as part of the Hudson Bay System Study (BaySys). Passive microwave scans and high-resolution 


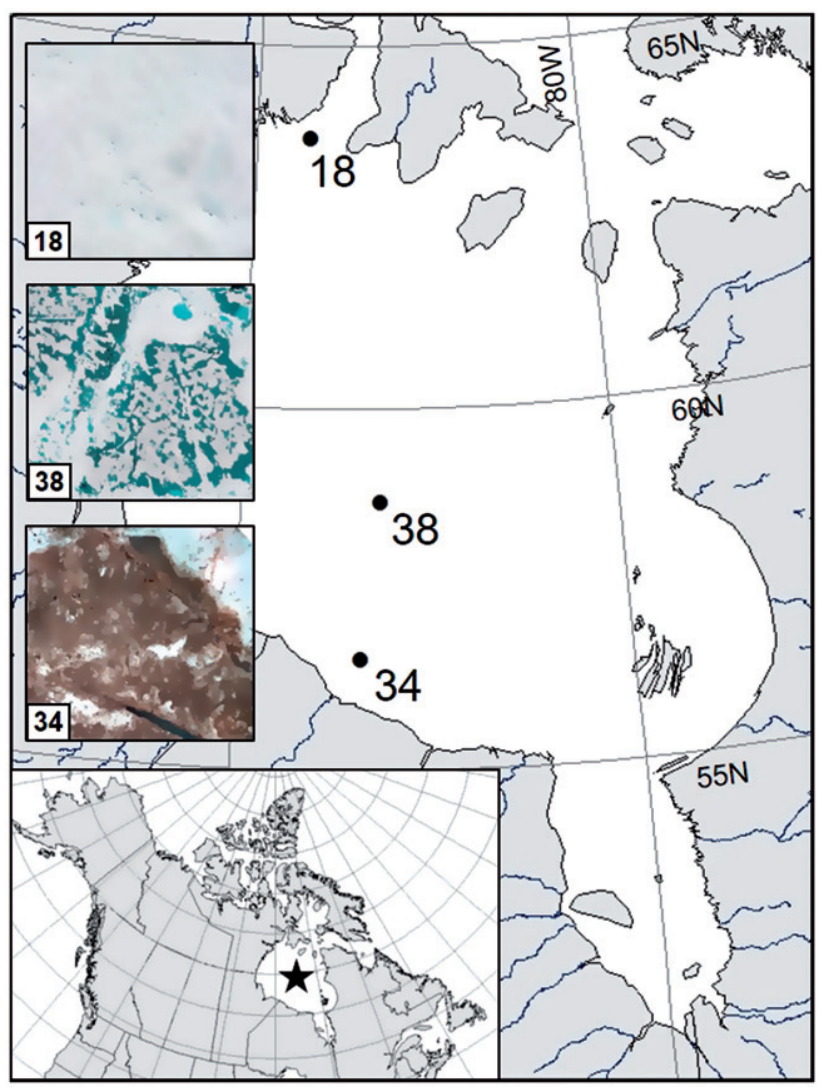

Figure 1. Survey locations within Hudson Bay, with rivers shown in dark blue. Aerial images of each survey captured by UAV show general ice surface conditions.

UAV optical imagery were collected for three survey sites across central Hudson Bay, Canada (Figure 1). Survey 34 consisted of highly sediment-laden ice, whereas surveys 18 and 38 consisted of sediment-free ice. These three sites were selected for this analysis as ice at each location had similar surface thermophysical properties (Table 1), allowing for comparison of passive microwave signatures, geophysical and thermophysical properties. The ice surface roughness of survey 34 was extremely high (Figure 2), which will be explored further in this research through UAV data.

\section{UAV data}

UAV optical imagery were captured using a DJI Phantom 4 Pro quadcopter, with a 20 MP RGB camera payload. A DJI Mavic Air quadcopter was also used when flight extent and time were limited (for survey 34), having a $12 \mathrm{MP}$ RGB camera payload. Flight surveys were pre-programmed using Map Pilot for DJI (C)2019 Drones Made Easy, www.dronesmadeeasy. com/Articles.asp? $\mathrm{ID}=254$ ), specifying a gridded flight path over the sampled floe. Surveys 18 and 38 were flown at an altitude of $60 \mathrm{~m}$ to prevent interference
Table 1. Sampled physical property data for all floes.

\begin{tabular}{lccc}
\hline & \multicolumn{3}{c}{ Survey number } \\
\cline { 2 - 4 } & 18 & 34 & 38 \\
\hline Date of collection & June 8, & June 21, & June 23, \\
& 2018 & 2018 & 2018 \\
Ice surface temperature $\left({ }^{\circ} \mathrm{C}\right)$ & -0.1 & -0.1 & -0.3 \\
Ice thickness $(\mathrm{cm})$ & 96 & 1150 & 108 \\
Average snow depth $(\mathrm{cm})$ & 6 & 1 & 3 \\
Average snow temperature $\left({ }^{\circ} \mathrm{C}\right)$ & 0 & 0 & 0 \\
Snow wetness & Wet & Wet & Wet \\
Snow grain size $(\mathrm{mm})$ & 3 & 3 & 3 \\
Air temperature $\left({ }^{\circ} \mathrm{C}\right)$ & 0 & 5.8 & 6.8 \\
\hline
\end{tabular}

from the ship's radar system on communication between the ground station and UAV. Due to the uniqueness of the floe topography of survey 34 , images were captured at a lower altitude $(20 \mathrm{~m})$ to allow for high-resolution surface reconstruction (horizontal spatial resolution: survey $18=2.4 \mathrm{~cm}$, survey $34=7 \mathrm{~mm}$ and survey $38=2.2 \mathrm{~cm}$ ). Images were captured at an interval to ensure an along-track and across-track overlap of $70 \%$ to allow for the generation of orthomosaics and digital elevation models (DEM) using photogrammetric techniques. The GPS onboard the DJI Phantom 4 Pro and Mavic rely on satellite positioning (GNSS) from GPS and GLONASS, having a reported global accuracy of approximately $0.1 \mathrm{~m}$ vertically and $1.5 \mathrm{~m}$ horizontally for absolute positioning (www.dji.com/ca/phantom-4-pro/info, www.dji.com/ca/ mavic-air/info). Spatial coverage of UAV surveys was limited by the battery flight time, with surveys being programmed as large as possible while still fitting within one battery lifespan, spanning $0.12 \mathrm{~km}^{2}$ (survey 18 and 38 ) and $0.013 \mathrm{~km}^{2}$ (survey 34 ).

\section{Surface-based radiometer data}

Sea ice surface emissions in the microwave region were measured using a surface-based radiometer (SBR) mounted on the port side of the CCGS Amundsen, approximately $12 \mathrm{~m}$ above sea level. The SBR consists of three dual-polarized (vertical and horizontal) radiometers, simultaneously taking measurements at frequencies of 19,37 , and $89 \mathrm{GHz}$. Internal sensitivities of $0.04 \mathrm{~K} \quad(19 \mathrm{GHz}), \quad 0.03 \mathrm{~K}$ $(37 \mathrm{GHz})$, and $0.08 \mathrm{~K}(89 \mathrm{GHz})$ are reported in the manufacturer's (Radiometrics) specifications. A camera is also housed in the system, capturing images of the approximate field of view (FOV) of the radiometer. The ship was maneuvered beside an ice floe of interest, oriented so the prevailing wind was on the opposite side of the measured floe. This held the floe in a stable position throughout SBR data collection, verified by coincident image capture. SBR scans were completed over the same ice floes for which UAV 


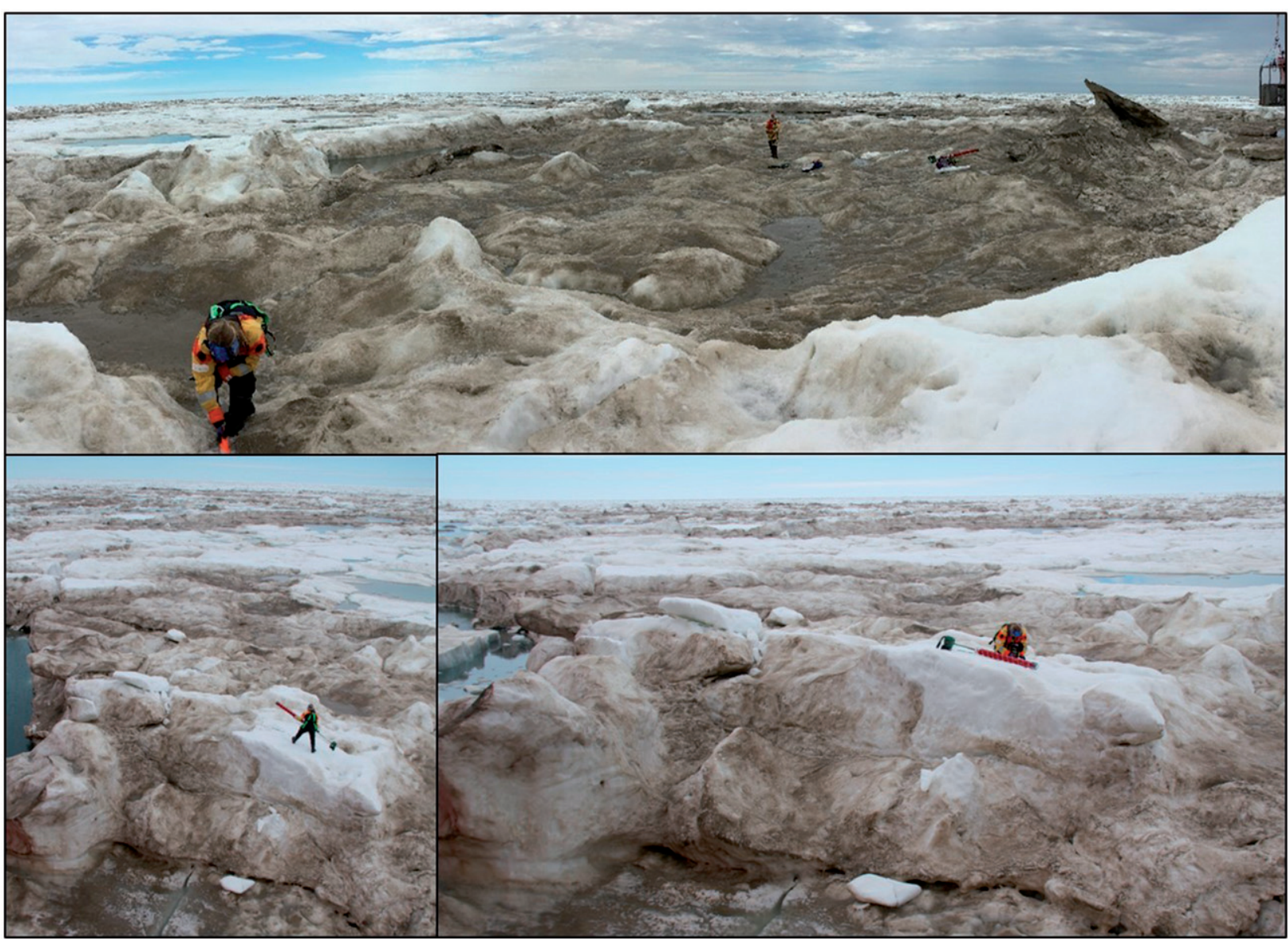

Figure 2. Oblique images captured of survey 34 , showing the magnitude of ice surface elevation variability and sediment loading.

imagery was captured. Calculation of the area of the SBR FOV is discussed in the section on FOV analysis.

The SBR system was mounted onto a rotating positioning system, allowing for the incidence angle of the SBR to be changed. At each survey site, the SBR was programmed to scan between incidence angles of $45^{\circ}$ and $70^{\circ}$ in $5^{\circ}$ steps, with radiometric measurements being captured once per incidence angle. Between 5 and 8 complete scans were completed for each floe (5 for surveys 18 and 38,8 for survey 34 ), with $\mathrm{T}_{\mathrm{B}}$ readings for each incidence angle being averaged over the entire period. All FOVs measured were fully illuminated by the sun and not impacted by the shadow of the ship, verified by coincident image capture by the camera housed in the SBR. The duration of SBR measurements lasted approximately 20 minutes.

Scans of a cold source (clear sky) and a hot source (ECCOSORB ${ }^{\circledR}$ high-loss microwave absorbing pads) were collected before each SBR data collection following methods from Asmus and Grant (1999), for which a 2-point data verification was completed to verify internal instrument calibration. A single calibration before each SBR measurement was determined to be sufficient for instrument calibration, as the duration of each SBR measurement period lasted 20 minutes, during which minimal instrument drift is expected.

\section{Physical sampling}

In-situ physical sampling was conducted coincident with the scanning area of the SBR to capture the pertinent physical and thermal variables influencing the measured $\mathrm{T}_{\mathrm{B}}$. Sampling was conducted after all SBR measurements were collected, falling within 1 hour of the last SBR measurement. Ice surface temperature, snow temperature, air temperature, snow depth, snow wetness, snow grain size, and temperature and salinity profiles through the ice were collected in situ at 3 locations coincident with the radiometer field of view. Surface measurements were averaged to gain a general understanding of the floe surface properties within the SBR FOV (Table 1). Sediment samples were also collected for the surface of survey 34 and analyzed for grain size distribution using a Microtrac S3500 Particle Size Analyzer. An ice core was extracted from each floe and sampled at $10-\mathrm{cm}$ intervals for salinity and temperature. Ice sectioning was completed immediately following temperature measurements and placed in sealed containers to prevent drainage of 


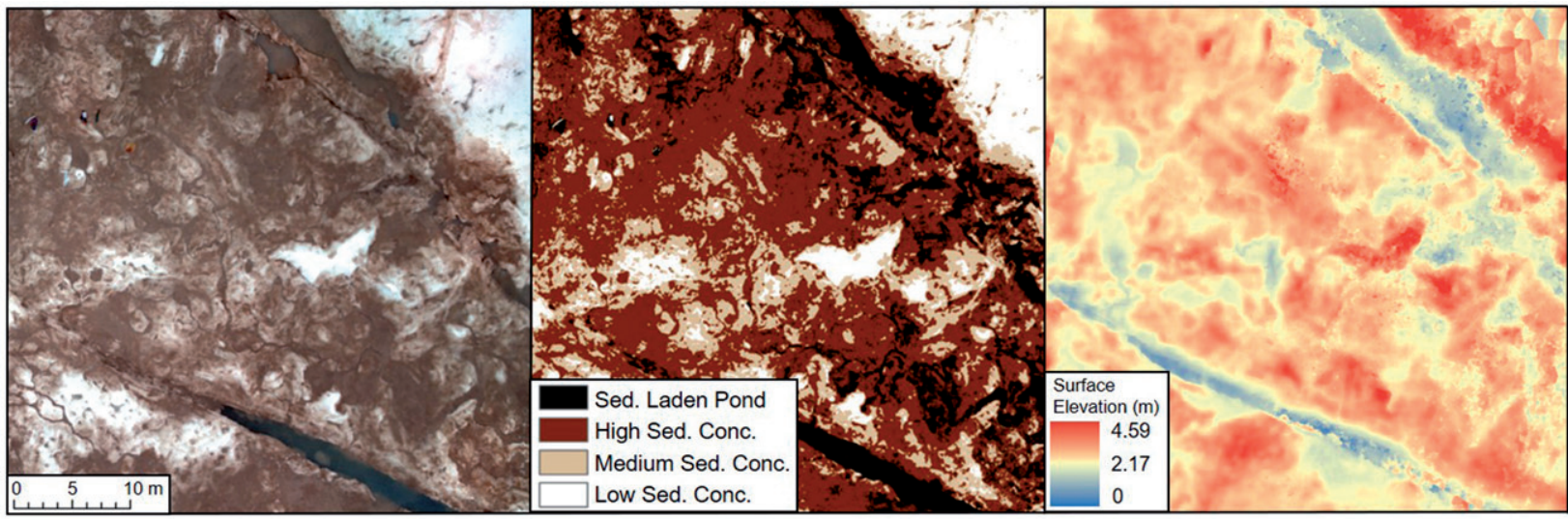

Figure 3. From left to right: optical imagery orthomosaic, sediment concentration map, and DEM for survey 34 generated from UAV imagery.

brines from the ice sections. Cores were taken for the full thickness for stations 18 and 38; however, ice thickness was too large for survey 34 , and therefore only the top meter of ice was analyzed. Total ice thickness is provided in Table 1, with thickness for survey 34 being estimated from ice freeboard determined from UAV DEMs. All salinity measurements were melted onboard, allowed to equilibrate to ambient temperature and measured using a SensION5 conductivity meter, precise to $\pm 0.1 \mathrm{ppt}$.

\section{Data processing methods}

\section{Orthophoto and DEM generation}

UAV image sets were stitched based on geolocation to generate a single orthomosaic for each site using the Pix $4 \mathrm{D}^{\circledR}$ image processing software (www.pix4d.com). DEMs for each survey site were generated from UAV imagery using Pix4D software, based on photogrammetric methods. Photogrammetry does not allow for the detection of melt pond depth based on theory presented in Landy et al. (2014), meaning that melt pond areas are represented as a single water elevation value. Relative spatial resolution of each UAV survey are as follows: $2.4 \mathrm{~cm}$ (survey 18), $7 \mathrm{~mm}$ (survey 34 ), and $2.2 \mathrm{~cm}$ (survey 38). Relative elevation accuracies noted for Pix $4 \mathrm{D}^{\circledR}$ DEM generation are 1-3 times the pixel size, meaning DEM accuracies are as follows: $2.4-7.2 \mathrm{~cm}$ (survey 18), 7-21 mm (survey 34), and $2.2-6.6 \mathrm{~cm}$ (survey 38 ). This study will assume a worst-case scenario for vertical accuracy, using $7.2 \mathrm{~cm}$, $21 \mathrm{~mm}$, and $6.6 \mathrm{~cm}$ as respective elevation accuracies.

Due to lack of ground control points, DEMs experienced radial distortion about the center of the scene. Distortion was corrected using a custom MATLAB R2016a program, which fits a quadratic function to each pixel row of the DEM iteratively, and then subtracts the resulting function from cell values removing the curved distortion. This results in a DEM displaying accurate relative heights within the scene. Absolute calibration for height between floes was not performed, as it was not required for this analysis and appropriate ground control points were not collected to co-register the scenes. This analysis is only comparing the surface elevation fluctuations between surveys through the use of surface statistics, therefore correcting the DEMs to an absolute geographical model is not necessary.

\section{Sediment concentration mapping}

An unsupervised classification method was used in ArcMap 10.5 to delineate 4 classes of sediment concentration/water on the ice surface. The Iso Cluster Unsupervised Classification method was chosen because existing knowledge of the integrated albedo of sea ice surface sediment in the Hudson Bay coastal region is limited. Classification was based on the knowledge that increasing sediment concentration would lead to a lower shortwave reflectance in all optical bands, as clean, snow covered ice has a very high reflectance and sediment has a low reflectance (Light et al. 1998; Huck et al. 2007).

A 4-class classification was chosen to generate 3 classes of increasing sediment concentration and a class representing sediment-laden melt ponds (Figure 3). Output classes were designated relative levels of sediment concentration (low, medium, or high) based on the output signature file, which provided the mean reflectance percentages for each class within each optical band, with the lowest sediment concentration having the highest reflectance percentage (Table 2). Results from this classification agree well with modeled surface spectral albedos provided by Huck et al. (2007): spectral albedo decreases with 
Table 2. Mean reflectance percentages for each sediment concentration class, generated by the unsupervised classification algorithm.

\begin{tabular}{lccc}
\hline Class & Red $(600 \mathrm{~nm})(\%)$ & Green $(540 \mathrm{~nm})(\%)$ & Blue $(460 \mathrm{~nm})(\%)$ \\
\hline Sediment-laden melt iond & 0.39 & 0.39 & 0.37 \\
High sediment concentration & 0.55 & 0.52 & 0.48 \\
Medium sediment concentration & 0.70 & 0.70 & 0.67 \\
Low sediment concentration & 0.88 & 0.92 & 0.93 \\
\hline
\end{tabular}

Wavelengths for peak sensitivities of the DJI Phantom 4 sensor within each spectral color band are provided.

Table 3. Basic statistics generated for elevation values found within each sediment concentration class for survey 34 .

\begin{tabular}{|c|c|c|c|c|c|c|c|}
\hline $\begin{array}{l}\text { Sediment } \\
\text { concentration class }\end{array}$ & $\begin{array}{c}\text { Class } \\
\text { population }\end{array}$ & $\begin{array}{l}\text { Minimum } \\
\text { elevation } \\
\text { value }(\mathrm{m})\end{array}$ & $\begin{array}{l}\text { Maximum } \\
\text { elevation } \\
\text { value }(\mathrm{m})\end{array}$ & Mean (m) & $\begin{array}{c}\text { Standard } \\
\text { deviation (m) }\end{array}$ & $\begin{array}{c}\text { 10th percentile } \\
\text { value }(\mathrm{m})\end{array}$ & $\begin{array}{c}\text { 90th percentile } \\
\text { value }(\mathrm{m})\end{array}$ \\
\hline High & 39864184 & 0.58 & 4.61 & 2.34 & 0.23 & 1.70 & 2.30 \\
\hline Medium & 23718524 & 0.61 & 4.61 & 2.43 & 0.25 & 1.74 & 2.42 \\
\hline Low & 19362656 & 0.66 & 4.57 & 2.55 & 0.28 & 1.81 & 2.66 \\
\hline
\end{tabular}

decreased wavelength over sediment-laden areas, whereas albedo increases for decreased wavelength over clean ice (within the range of wavelengths measured). Comparing the reflectance signature within each class to values provided by Huck et al. (2007), sediment concentration classes can be estimated to have the following concentrations: $0 \mathrm{~g} \mathrm{~m}^{-3}$ for low sediment concentration, $25 \mathrm{~g} \mathrm{~m}^{-3}$ for medium sediment concentration, $75 \mathrm{~g} \mathrm{~m}^{-3}$ for high sediment concentration, and $500 \mathrm{~g} \mathrm{~m}^{-3}$ for sediment-laden melt ponds.

\section{Sediment concentration/surface elevation correl- ation analysis}

Statistics relating sediment concentration to surface elevation were generated using the Zonal Statistics tool in ArcMap. This tool classifies each pixel of an underlying raster based on a classification raster layer, and then generates basic statistics for each class (mean, range, and standard deviation). This provided statistics for the elevation values found within each sediment concentration class (Table 3 ), which were then used to test the statistical significance of the relationship between sediment concentration and floe surface elevation. Elevation values within each class were then extracted and a histogram was generated to display the distribution of elevation values within each sediment concentration class (Figure 4). Basic statistics were generated for a $0.002 \mathrm{~km}^{2}$ subset area corresponding to the area used for surface roughness statistics generated in the next section. The rationale behind the use of a subset area is included in this section.

\section{Surface roughness quantification}

Surface roughness over a subset of the floe area was quantified by calculating the average root mean square

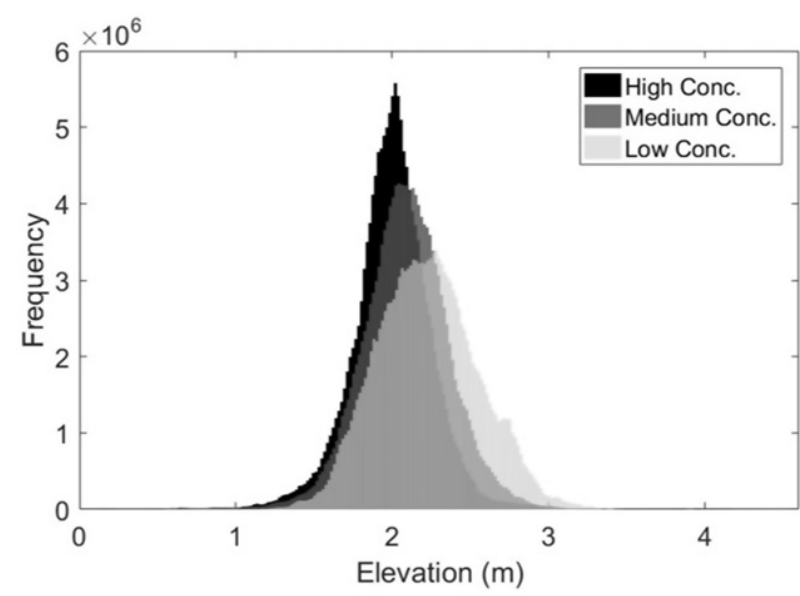

Figure 4. Histograms of elevation values falling within each sediment concentration class. All classes show a normal distribution around the mean, with mean value increasing for decreased sediment concentration.

(RMS) height and the correlation length across the survey area using MATLAB (Table 4). NaN values persisted in the DEM due to the irregular shape of the UAV survey area. To address this, a rectangular subset of the image was used so that $\mathrm{NaN}$ values could be removed from the DEM matrix so statistics could be properly calculated. Subset areas included the FOV of the SBR, being approximately $0.002 \mathrm{~km}^{2}$ to ensure similar subset areas were analyzed for each survey site.

Scripts for calculating correlation length across a 2D array were provided by Bergström et al. (2012). RMS height provides a statistic for the average deviation of elevation around the mean, whereas the correlation length describes the spatial scale on which elevation varies. The correlation length function was plotted for the $x$ - and $y$-directions across the survey, which represent the horizontal (east/west) and vertical (north/south) directions across the DEM, respectively. 
Table 4. Surface roughness metrics calculated for a subset of the floe area.

\begin{tabular}{lcccc}
\hline Survey number & $\begin{array}{c}\text { Average surface } \\
\text { elevation }(\mathrm{m})\end{array}$ & RMS height $(\mathrm{m})$ & $\begin{array}{c}\text { Average correlation } \\
\text { length } x \text {-direction }(\mathrm{m})\end{array}$ & $\begin{array}{c}\text { Average correlation } \\
\text { length } y \text {-direction }(\mathrm{m})\end{array}$ \\
\hline 18 & 0.126 & 0.006 & 1.74 & 1.788 \\
34 & 1.269 & 0.031 & 1.459 & 1.622 \\
38 & 0.360 & 0.005 & 2.035 & 1.969 \\
\hline
\end{tabular}

Histograms displaying the percent count of elevation values across the survey areas were generated to determine the distribution of elevation values for each survey. Percent count was chosen based on the magnitude of these data sets (Table 3). These metrics were used to compare the overall surface roughness between the sediment-laden floe and the surrounding non-sediment-laden floes.

\section{FOV analysis}

FOVs of each radiometer vary based on the frequency of measurement, ranging in area from $6.36 \mathrm{~m}^{2}$ to $6.62 \mathrm{~m}^{2}$ for a $55^{\circ}$ incidence angle at $12 \mathrm{~m}$ height. The overlap between FOVs of each measured frequency is substantial (similar to Figure 4 in Comiso et al. 1989); therefore, for simplicity in this analysis we represent the FOV area of the SBR based on dimensions of the 19 and $37 \mathrm{GHz}$ radiometer, both having antenna halfpower beam widths (HPBW) of $6^{\circ}$ in comparison with the HPBW of $89 \mathrm{GHz}$ of $5.88^{\circ}$.

The FOV of the passive microwave radiometer was calculated based on the height of the radiometer above sea level $(\sim 12 \mathrm{~m})$, the HPBW of the SBR antennas $\left(6^{\circ}\right)$, and the corresponding incidence angle of measurement (ranging from $45^{\circ}$ to $70^{\circ}$ ). From this, the centroid was plotted on UAV orthomosaics in relation to the position of the radiometer, and an approximation of the FOV of each incidence angle was plotted extending from this centroid (Figure 5). This allowed for the extraction of sediment concentration data and general surface characteristic descriptions from UAV data within the FOV of the radiometer, to determine the surface features influencing the measured $\mathrm{T}_{\mathrm{B}}$.

\section{Results}

\section{Sediment grain size}

For survey 34, surface sediment size distribution was measured to range between 9 and $80 \mu \mathrm{m}$, having a normal distribution around a median grain size of $28 \mu \mathrm{m}$. This grain size range falls within the class fine silt to very fine sand following the Wentworth Grain Size Classification (Wentworth 1922).
Previous research in the Eurasian Arctic/Fram Strait has shown approximately $80 \%$ of sediment grains found on sea ice surfaces in this area are $>16 \mu \mathrm{m}$ (Pfirman et al. 1989), with only minor grains coarser than $63 \mu \mathrm{m}$ (Larssen et al. 1987). In comparison, survey 34 grain size is slightly larger on average, suggesting influence from higher turbidity values or anchor rafting. Research into the sedimentology of this region and proposed mechanism of sediment entrainment in sea ice is being investigated in a separate study.

\section{Sediment concentration vs. surface elevation}

Generated statistics for sediment concentration in relation to surface elevation across survey 34 suggest that there is a negative relationship between sediment concentration and surface elevation based on calculated means (Table 3), with increased sediment concentration relating to lower surface elevation values (schematically illustrated in Figure 6).

Sediment concentration class histograms show that each class has a normal distribution of elevation values around the class mean, with class means increasing with decreased sediment concentration (Figure 4). Distributions of class elevation values are separable, with the 10th and 90th percentile values increasing for decreasing sediment concentration (Table 3).

To determine the statistical significance of this relationship, a $t$-test was completed to compare the elevation means of the low, medium and high sediment concentration classes. Results from the $t$-test show a $p$-value $<0.05$ (Table 5), suggesting a statistically significant relationship. Due to the magnitude of the class populations (on the order of 30 million), this conclusion cannot be confirmed to be absolute, due to the inability for statistical analyses to represent big data (Hofmann 2015). However, confidence intervals suggest that class means can be concluded to be different, with Cohen's $d$ statistic showing class separation by over a third of a standard deviation (Table 5). Despite the small numerical difference between class means $(0.089$ and $0.125 \mathrm{~m})$, differences are notable in comparison to elevation variations provided for non-sediment-laden floes (Table 4), suggesting that sediment concentration may have a significant correlation with surface elevation. 


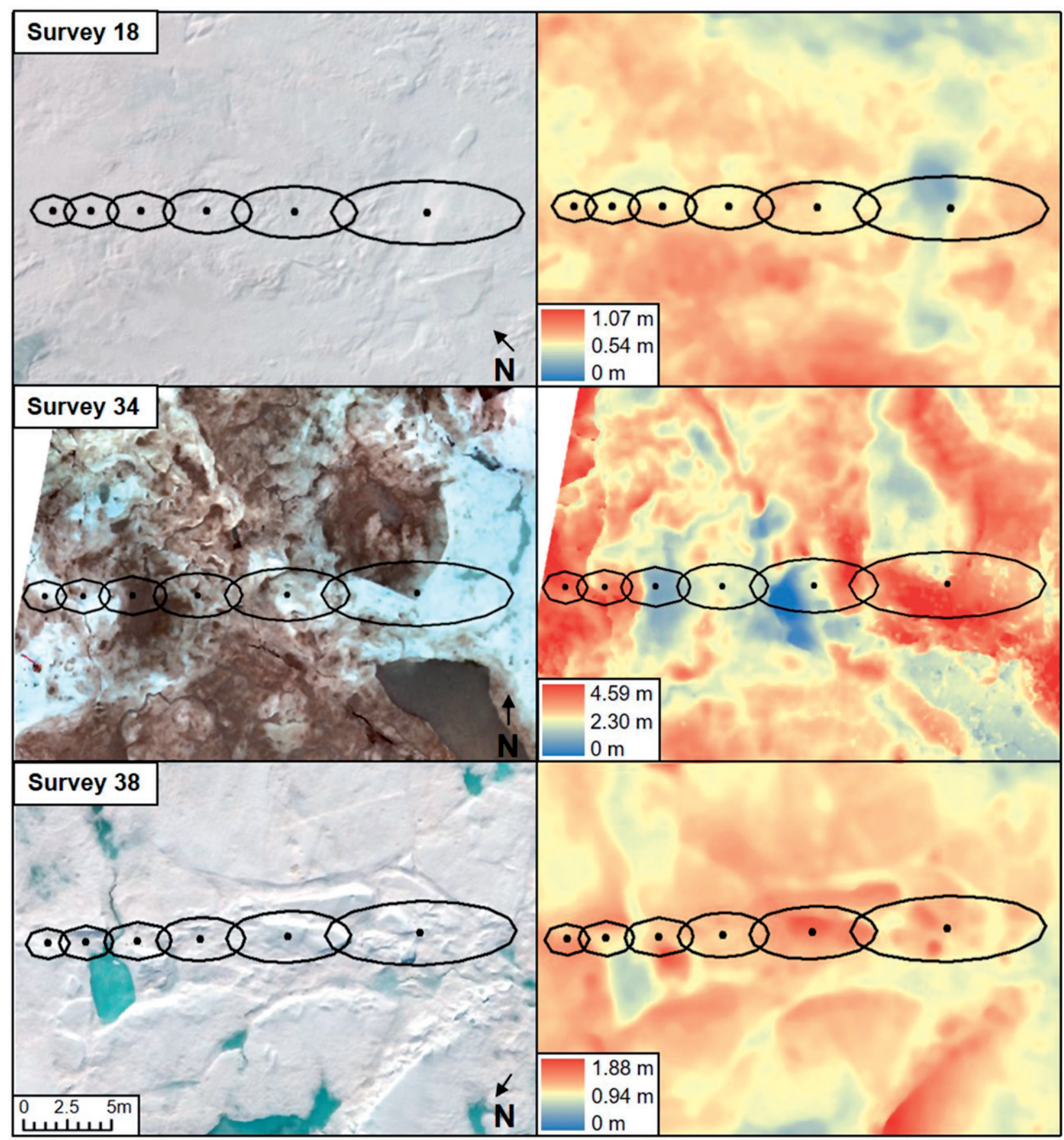

Figure 5. In situ radiometer FOV area for all incidence angles $\left(45^{\circ}-70^{\circ}\right)$ plotted across optical orthomosaic and DEM to display the approximate surficial features influencing measured TB at each angle.

\section{Surface statistics}

In this paper, the ice surface is defined as including the surface of melt ponds. As previously noted, DEMs represent melt pond areas as a single water level elevation. This leads to melt pond areas lowering the surface elevation variation across a DEM, influencing the resulting surface statistics of surveys 34 and 38 .

Results from the RMS height and correlation length calculation show that the sediment-laden sea ice floe has a more varied surface roughness compared to the

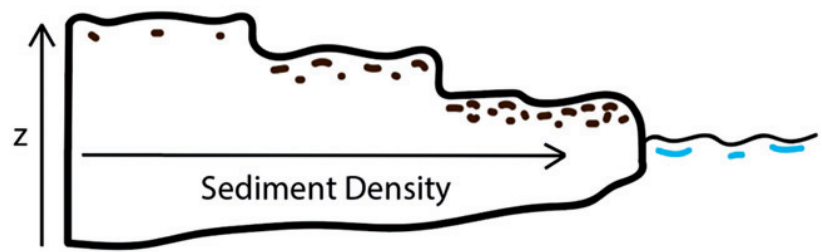

Figure 6. Conceptual drawing displaying the measured relationship between surface sediment density and sea ice elevation, with surface elevation decreasing with increased surface sediment concentration. 
Table 5. Results from the $t$-test and Cohen's $d$ analysis, comparing mean elevation values for each sediment concentration class.

\begin{tabular}{lcc}
\hline & High sediment vs. medium sediment & Medium sediment vs. low sediment \\
\hline Difference & 0.089 & 0.125 \\
Standard error & 0 & 0 \\
$95 \%$ confidence interval & 0.0889 to 0.0891 & 0.1248 to 0.1252 \\
$t$-statistic & 1439.358 & 1551.463 \\
Degrees of freedom & $63,582,706$ & $43,081,178$ \\
Significance level & $P<0.0001$ & $P<0.0001$ \\
Cohen's $d$ & 0.368911 & 0.472996 \\
\hline
\end{tabular}

adjacent non-sediment-laden floes (surveys 18 and 38) (Table 4). The RMS height of survey 34 was calculated to be $0.031 \mathrm{~m}$, meaning that the surface elevation across the subset area varies by $0.031 \mathrm{~m}$ on average, compared to the remaining surveys who have an RMS height equal to or less than $0.006 \mathrm{~m}$. Survey 34 has a smaller correlation length in both the $x$ - and $y$-directions in comparison with the remaining floes (Table 4). This means that the surface elevation across the survey 34 subset area varies on a smaller spatial scale in comparison to the non-sediment-laden floes subset area. All floe surfaces exhibit a degree of anisotropy, as indicated by differences between the correlation functions in $x$ - and $y$-directions. Considering the similarity between correlation length functions in the $x$ - and $y$-directions, survey 34 appears to be nearly isotropic (Figure 7).

Comparing the elevation histograms, all surveys have a unimodal distribution; however, each survey has a unique spread and skewness of elevation values (Figure 8). Survey 18 has a slightly right-skewed distribution, with a small spread across a small range of elevation values. Survey 38 has a wider range of elevation values in comparison to survey 18 and is slightly negatively skewed. Survey 34 shows the largest skewness of data, being right-skewed across a wide range of elevation values. This comparison shows that survey 34 has the largest range of elevation values and has the greatest skewness, meaning that survey 34 has the greatest difference between the elevation mean and mode.

\section{Floe surface characterization}

Physical sampling of each floe showed that the surface of each floe was experiencing melt, as fresh liquid water was present on each of the floe surfaces and average snow temperatures were $0^{\circ} \mathrm{C}$ (Table 1). The snow layer consisted of large $(3 \mathrm{~mm})$ grains with liquid water present, but not saturating the layer. Salinity profiles show that survey 34 has a lower bulk salinity in comparison to surveys 18 and 38 , being a result of formation in brackish water or experiencing
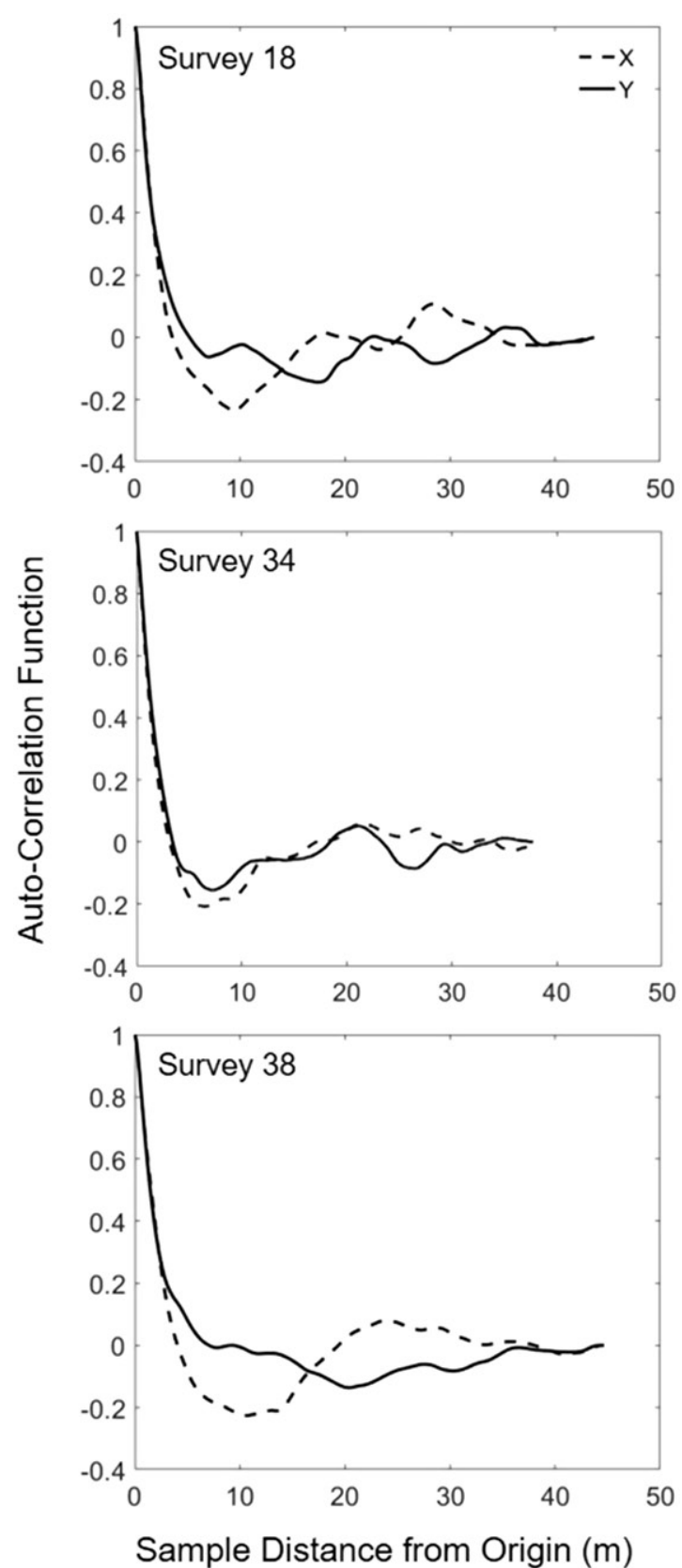

Figure 7. Correlation length function for the $x$ - (north/south) and $y$ - (east/west) directions for all surveys.

a more advanced melt allowing brines to drain from the top of the ice profile (Figure 9). Despite this difference in salinity through the ice at depth, ice surface 


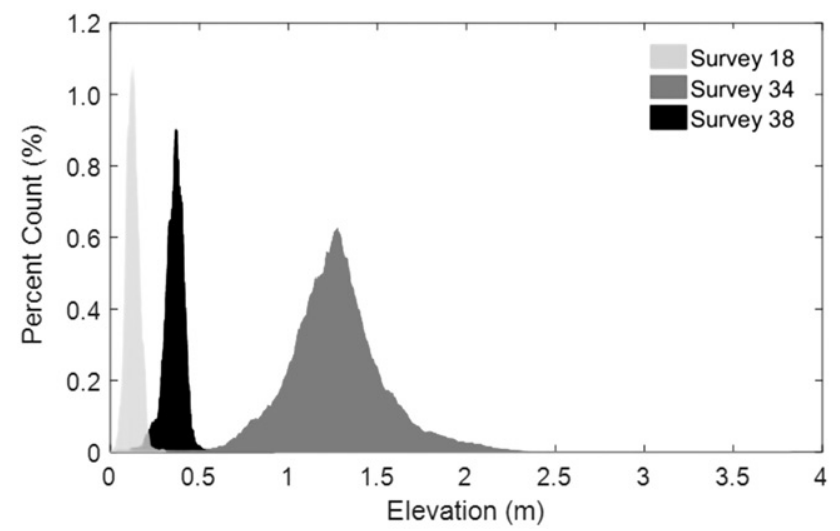

Figure 8. Histograms displaying percent count of elevation values for the whole survey area for each survey site. Surveys 18 and 38 have lower surface elevation means, with narrow distributions around the mean in comparison with survey 34 .

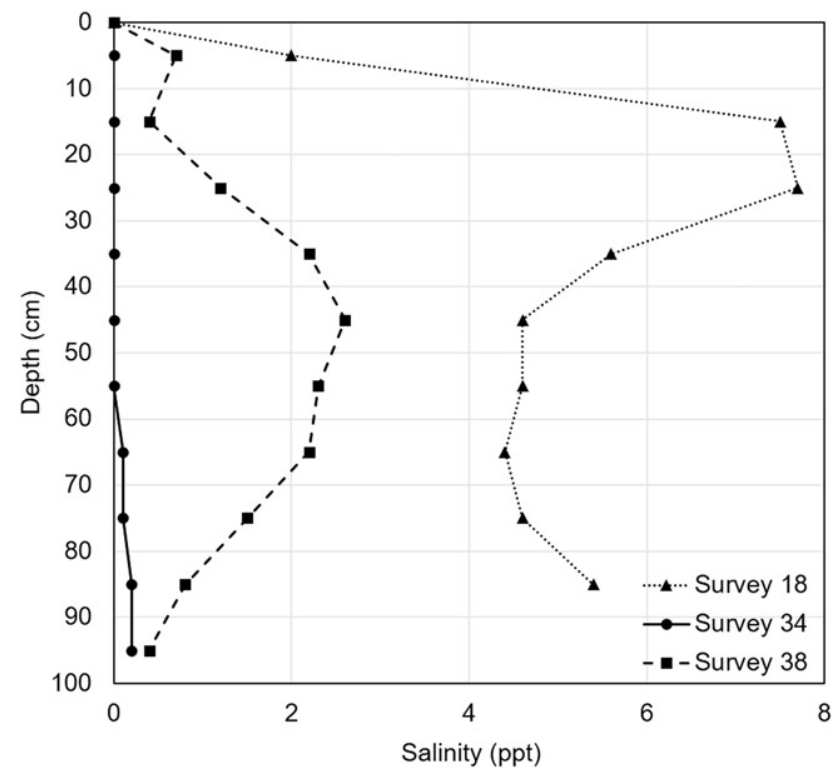

Figure 9. Salinity profiles for the top meter of sampled floes, with a depth of $0 \mathrm{~cm}$ representing ice/snow interface salinity.

properties are of primary importance for $T_{B}$ analysis as this is where the majority of measured emissions originate due to the low penetration depth of electromagnetic energy through liquid water (Onstott et al. 1987). This study will only consider differences in ice surface properties to explain differences in $T_{B}$ between surveys.

The full FOV area of survey 18 appears to be over a smooth ice/snow area (Figure 5). The FOV of $70^{\circ}$ contains an area of decreased elevation in comparison to FOV of lower incidence angles, meaning this incidence angle may show effects related to a rougher surface. Overall, the measured $\mathrm{T}_{\mathrm{B}}$ for survey 18 is under the influence of $\sim 6 \mathrm{~cm}$ of a smooth, wet snow layer (Table 1).
The full FOV area of survey 38 includes a small portion of a liquid melt pond in the $50^{\circ}$ and $55^{\circ}$ incidence angle FOV (Figure 5). Incidence angles greater than $55^{\circ}$ include rough topography. This means that measured $\mathrm{T}_{\mathrm{B}}$ or survey 38 are under the influence of surface liquid water in lower incidence angles, rough surface topography in higher incidence angles, as well as a $\sim 3 \mathrm{~cm}$ layer of wet snow (Table 1 ).

Sediment concentration within the full FOV of survey 34 was non-representative of sediment concentration across the floe area. Sediment-laden melt ponds and areas of high sediment concentration were underrepresented within the FOV, whereas low sediment concentration areas were greatly overrepresented (Table 6). As well, different surface features are being viewed across the swath of incidence angles, as this is a highly inhomogeneous surface (Figure 5). Incidence angles of $45^{\circ}, 50^{\circ}$, and $65^{\circ}$ contain a mixture of clean snow and sediment-laden snow, appearing to be a somewhat even combination of the three sediment classes. The FOV of $55^{\circ}$ is centralized within a highly sediment-laden melt pond, with the FOV of $60^{\circ}$ containing a mixture of this melt pond along with medium sediment concentration areas. The FOV of $70^{\circ}$ is situated over a large area of low sediment concentration, representing the smallest area of medium or high sediment-laden ice of all FOVs. Therefore, it should be taken into consideration that each FOV is representative of a different combination of the three sediment-laden classes, which is predicted to influence the respective $T_{B}$ of each incidence angle. $T_{B}$ of survey 34 will be under the influence of a highly inhomogeneous surface containing a combination of sedimentladen liquid water, a sediment/snow mixture of a depth $<1 \mathrm{~cm}$ and sediment free snow of an approximate depth of $1 \mathrm{~cm}$.

\section{Passive microwave $T_{B}$}

Over the range of incidence angles sampled, on average horizontally polarized $T_{B}$ decrease with increased angle whereas vertically polarized $\mathrm{T}_{B}$ remain the same (Figure 10 ). $T_{B}$ for survey 18 have a greater range of values across incidence angles, with the difference between horizontally polarized $(\mathrm{H}-\mathrm{pol})$ and vertically polarized (V-pol) $\mathrm{T}_{\mathrm{B}}$ of the same frequency slightly increasing throughout the whole scan (Figure 10). $\mathrm{T}_{\mathrm{B}}$ for survey 38 show a similar gradual separation between $\mathrm{H}$-pol and $\mathrm{V}$-pol with increased incidence angle; however, the difference in $\mathrm{T}_{\mathrm{B}}$ for each polarization is smaller (Figure 10). Another similarity between these 2 surveys is that $89 \mathrm{GHz} \mathrm{H}$-pol and V-pol have 
Table 6. Total class coverage for survey 34 for the whole floe area and the FOV area.

\begin{tabular}{lcc}
\hline & Whole floe area coverage (\%) & FOV area coverage (\%) \\
\hline Sediment-laden melt pond & 22 & 15 \\
High sediment concentration & 38 & 16 \\
Medium sediment concentration & 22 & 29 \\
Low sediment concentration & 18 & 41 \\
\hline
\end{tabular}

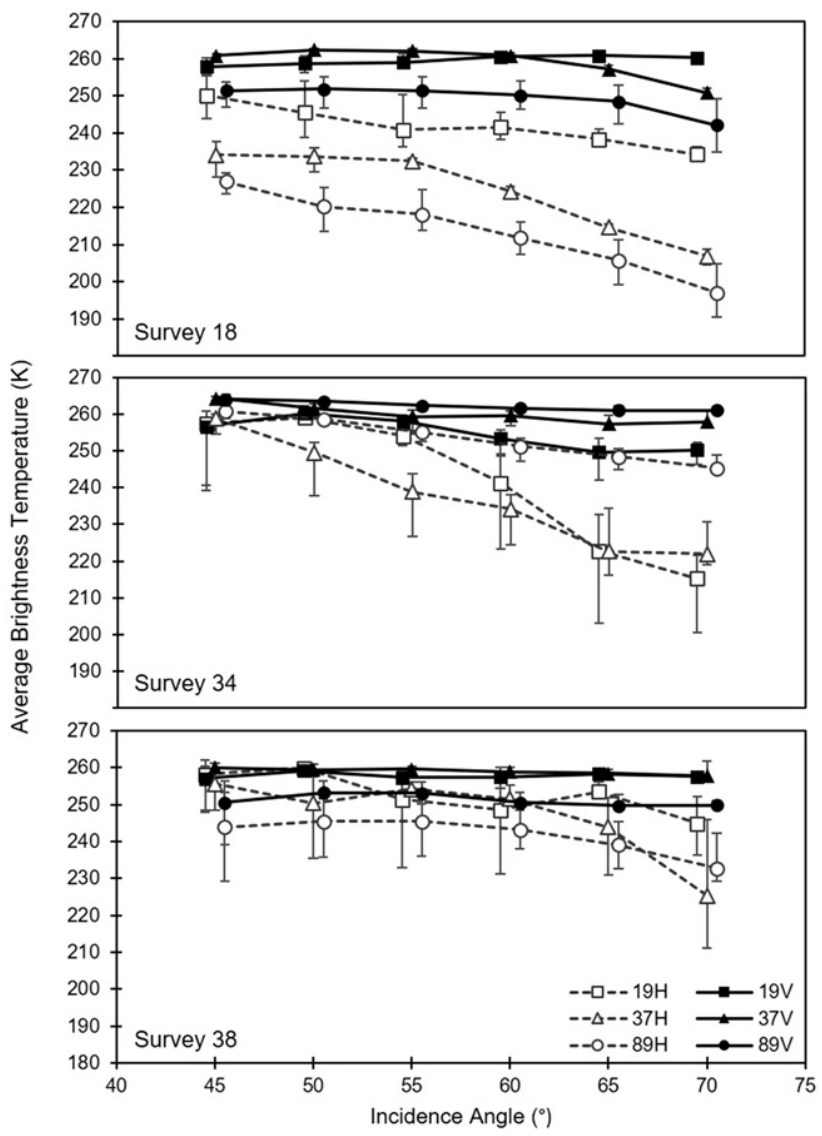

Figure 10. $T_{B}$ for all frequencies/polarizations between $45^{\circ}$ and $70^{\circ}$, with vertical bars showing the maximum and minimum measured brightness temperatures. Values for $19 \mathrm{GHz}$ and $89 \mathrm{GHz}$ are offset along the $x$-axis by $-0.5^{\circ}$ and $0.5^{\circ}$, respectively, for better visualization of the data.

the lowest $T_{B}$ for almost all incidence angles across the scan. This is not observed for survey 34 , where $89 \mathrm{GHz} \mathrm{H}$-pol and V-pol have the highest $\mathrm{T}_{\mathrm{B}}$ across all incidence angles out of all respectively polarized channels (Figure 10). Survey 34 shows a large increase in the difference between $\mathrm{H}$-pol and V-pol $\mathrm{T}_{\mathrm{B}}$ for 19 and $37 \mathrm{GHz}$ channels, whereas $89 \mathrm{GHz}$ shows a more gradual increase in difference. Differences noted in $\mathrm{T}_{\mathrm{B}}$ of survey 34 are proposed to be a result of increased surface melt and deformation influenced by surface sediments, which will be examined further in a later section.

The range of $T_{B}$ values at each incidence angle tends to be high for inhomogeneous floe surfaces. Survey 38 has a range in $T_{B}$ as a high as $35 \mathrm{~K}$ for

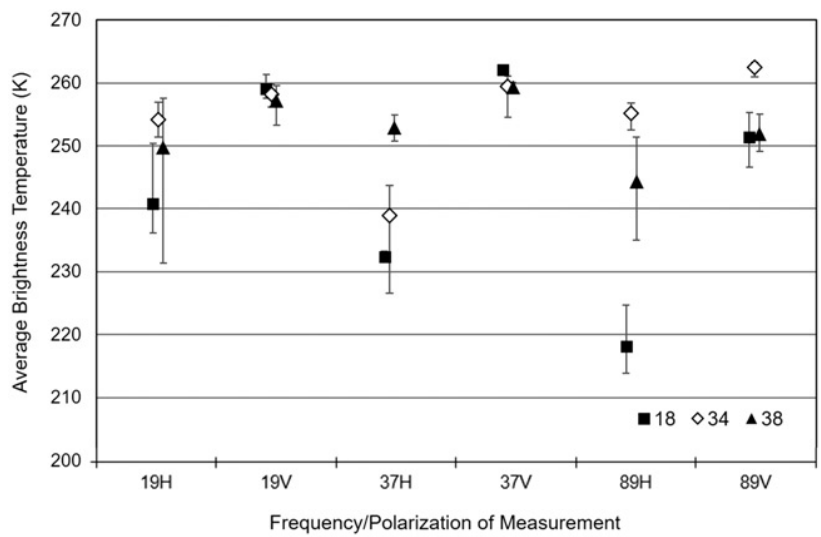

Figure 11. Average $T_{B}$ for the $55^{\circ}$ incidence angle at each survey location, with vertical bars showing the maximum and minimum measured brightness temperatures. Values for $19 \mathrm{GHz}$ and $89 \mathrm{GHz}$ are offset along the $x$-axis for better visualization of the data.

$37 \mathrm{GHz} \mathrm{H}$-pol at $70^{\circ}$, and survey 34 has a maximum range in $\mathrm{T}_{\mathrm{B}}$ of $30 \mathrm{~K}$ for $19 \mathrm{H}$-pol at $65^{\circ}$, whereas the highest range in $\mathrm{T}_{\mathrm{B}}$ for survey 18 is $15 \mathrm{~K}$ for $19 \mathrm{H}$-pol at $50^{\circ}$ (Figure 10). $\mathrm{T}_{\mathrm{B}}$ for $\mathrm{H}$-pol has higher ranges in comparison to the $\mathrm{V}$-pol counterpart for all frequencies and all surveys (Figure 10). This difference is greatest for survey 38 , where $\mathrm{H}$-pol $\mathrm{T}_{\mathrm{B}}$ has average ranges of $14.7 \mathrm{~K}, 16.3 \mathrm{~K}$ and $15.6 \mathrm{~K}$ (for 19,37 , and $89 \mathrm{GHz}$, respectively), whereas $\mathrm{V}$-pol has average ranges of $5 \mathrm{~K}, 2.6 \mathrm{~K}$, and $6.3 \mathrm{~K}$.

Detailed results of $\mathrm{T}_{\mathrm{B}}$ values for the $55^{\circ}$ incidence angle (corresponding to satellite-based sensor AMSR2 $\left(55^{\circ}\right.$ ) and AMSR-E (55 ) (Du et al. 2014)) are given in Figure 11. Through this, the influence of surface sediment on satellite-detected $\mathrm{T}_{B}$ can be hypothesized. Physical properties influencing $\mathrm{T}_{B}$ measured at $55^{\circ}$ are as follows: survey 18 - smooth, wet snow layer of $\sim 6 \mathrm{~cm}$ depth; survey 34 - highly sediment-laden melt pond with some influence from a sediment-laden snow pack of $<1 \mathrm{~cm}$ depth; survey 38 - rough, wet snowpack of $\sim 3 \mathrm{~cm}$ depth, with some influence from a melt pond (Figure 5).

$\mathrm{T}_{\mathrm{B}}$ values at the $55^{\circ}$ incidence angle for each survey show a unique pattern across each frequency/polarization combination (Figure 11). $T_{B}$ values for $V$-pol show lower variation across measurement frequency in comparison to $\mathrm{H}$-pol for all surveys. The largest variation in $T_{B}$ across measurement frequency for the 
$\mathrm{V}$-pol is $11 \mathrm{~K}$ (survey 18) and the largest variation in $\mathrm{T}_{\mathrm{B}}$ for $\mathrm{H}$-pol across frequencies is $23 \mathrm{~K}$ (survey 18 ).

Comparing $\mathrm{T}_{\mathrm{B}}$ for survey 34 (sediment-laden ice) to the remaining surveys (non-sediment-laden ice), survey 34 has the highest $T_{B}$ values measured for $89 \mathrm{GHz}$ on average, having an $89 \mathrm{GHz} \mathrm{V}$-pol $\mathrm{T}_{\mathrm{B}}$ $\sim 10 \mathrm{~K}$ greater than surveys 18 and 38 , which both have the same $\mathrm{T}_{\mathrm{B}}$ at $89 \mathrm{GHz} \mathrm{V}$-pol (Figure 11).

Regarding the polarization difference between measurements at the same frequency, survey 18 shows the largest polarization difference in $\mathrm{T}_{\mathrm{B}}$, with $33 \mathrm{~K}$ at $89 \mathrm{GHz}$, decreasing to a difference of $18 \mathrm{~K}$ at $19 \mathrm{GHz}$ (Figure 11). Survey 38 has a considerably smaller polarization difference, showing little variation across measurement frequency: $7 \mathrm{~K}, 6 \mathrm{~K}$, and $7 \mathrm{~K}$ at 19,37 , and $89 \mathrm{GHz}$, respectively. In contrast, survey 34 shows small polarization differences at $19 \mathrm{GHz}(4 \mathrm{~K})$ and $89 \mathrm{GHz}(7 \mathrm{~K})$ but has a large polarization difference at $37 \mathrm{GHz}(20 \mathrm{~K})$.

\section{Discussion}

\section{Sediment concentration}

Spatial analysis of the distribution of sediment concentration in relation to corresponding ice surface elevation suggests that there is a negative relationship between sediment concentration and surface elevation (Figure 6). As a result, the distribution of surface sediment can be related to the overall surface variability of the ice floe, which has been verified through the calculation of surface roughness metrics (Table 4). Results from this study strongly suggest that sediment presence on the surface of sea ice influences the evolution of surface topography during the melt period, leading to high surface elevation variability.

The proposed mechanism that relates surface sediment distribution to sea ice surface elevation variation is increased absorption of solar radiation by sediment particles. Sediment particles have a lower albedo than the surrounding sea ice surface, meaning that they will absorb more solar radiation in comparison to a clean ice surface with a high albedo (Light et al. 1998). Due to this, sediment on the ice surface will absorb more solar energy, leading to an increase of surface temperatures and increased melt rates (Figure 6). Surface roughness could also be generated through anchor rafting, during which ice formation begins on the sea floor, after which ice fragments release from the floor and act as the surface for new ice formation (Reimnitz et al. 1987). This freezing could occur irregularly dependent on the size and saturation underlying sediments, generating varied ice roughness
(Reimnitz et al. 1987). We speculate that the surface roughness observed in this research is generated under the influence of a combination of both processes. Further research is required to discern surface roughness generated by sea ice formation (i.e., anchor rafting, dynamic growth in turbulent areas) and surface roughness driven by uneven distribution of sediments across the ice surface.

\section{Brightness temperature}

The thermophysical properties of the sea ice surface must first be taken into consideration when analyzing the effect of surface roughness on measured $T_{B}$. The presence of liquid water has a large influence on the emission of the ice surface, as emissions from the ice body itself are blocked due to the low penetration depth of microwave frequencies into liquid water (Ulaby et al. 1986). As a result, the $\mathrm{T}_{\mathrm{B}}$ of all floes should experience some influence of liquid water on their emission pattern, as liquid water was present in the surface layer at all survey sites (Table 1). As well, sea ice surface sediment is proposed to increase the presence of liquid water on the ice surface due to increased melt rates, making liquid water an important variable to consider when analyzing $\mathrm{T}_{\mathrm{B}}$.

We first consider the effect of water in liquid phase on measured $\mathrm{T}_{\mathrm{B}}$. During the first stages of melt on the surface of first-year sea ice, liquid water presence in the snow pack has been shown to increase $T_{B}$ in all frequencies relative to the initial dry snow pack $T_{B}$, due to the contribution of emissions from liquid water droplets in the snow medium (Eppler et al. 1992; Garrity 1992; Barber 2005). During this melt period, higher frequencies have the lowest $\mathrm{T}_{B}$ with measured $\mathrm{T}_{\mathrm{B}}$ increasing for decreased frequency (Onstott et al. 1987; Barber 2005). Survey 18 is expected to agree with this pattern as liquid water persisted in the snowpack; however, melt ponds had not begun to form, denoting an early stage of melt (Figure 5). Advanced melt including melt pond formation drives the decrease of $\mathrm{T}_{\mathrm{B}}$ in lower frequencies (19 and $37 \mathrm{GHz}$ ), but an increase in higher frequencies in comparison to the early-stage melt signature described above (Onstott et al. 1987; Barber 2005). This is expected to agree with surveys 34 and 38 , as they were sampled later into the melt season and were experiencing signs of advanced melt such as extensive melt ponding (Figure 5).

For measured $T_{B}$, each survey agrees relatively well with the evolution of $\mathrm{T}_{\mathrm{B}}$ during the melt period provided in Onstott et al. (1987) and Barber (2005). 
Survey 18 agrees well with $\mathrm{T}_{\mathrm{B}}$ reported for early melt, as $T_{B}$ increases for decreased frequency of measurement considering each polarization separately for all measurement channels excluding $19 \mathrm{GHz} \quad \mathrm{V}$-pol (Figure 11). Survey 34 agrees best with $\mathrm{T}_{B}$ reported for advanced melt, as $89 \mathrm{GHz}$ has either similar or higher values than $T_{B}$ of lower frequencies (Figure 11). Survey 38 agrees with this emission pattern as well; however, $T_{B}$ values for $89 \mathrm{GHz}$ are lower than those measured for survey 34 . This could suggest that survey 34 is at a later stage of surface melt progression in comparison to survey 38 , as $\mathrm{T}_{\mathrm{B}}$ for higher frequencies are expected to increase as melt progresses from early melt to advanced melt (Onstott et al. 1987; Barber 2005).

To assess the effects of surface roughness on measured $T_{B}$, we can first look at how $T_{B}$ changes with change in incidence angle of measurement. For firstyear ice it is expected that the difference between $\mathrm{V}$-pol and $\mathrm{H}$-pol $\mathrm{T}_{\mathrm{B}}$ will increase with increased incidence angle (Stroeve et al. 2006; Grenfell and Comiso 1986; Grenfell and Lohanick 1985). Our data for survey 34 shows this as well, with the largest separation of V-pol and $\mathrm{H}$-pol $\mathrm{T}_{\mathrm{B}}$ occurring for 19 and $37 \mathrm{GHz}$ (Figure 10). The $89 \mathrm{GHz}$ channel does not experience this similar pattern across the sediment-laden floe, with the separation between $\mathrm{V}$-pol and $\mathrm{H}$-pol $\mathrm{T}_{\mathrm{B}}$ only increasing slightly with increased incidence angle.

Previous research on the impact of surface roughness on observed $\mathrm{T}_{\mathrm{B}}$ during early melt indicates that the $89 \mathrm{GHz}$ frequency is more sensitive to surface roughness than the 19 and $37 \mathrm{GHz}$ frequencies due to the low penetration depth of higher frequencies (Gupta and Barber 2015). To compare this with our data, only surveys 34 and 38 will be considered, as survey 18 is experiencing an earlier stage of melt, leading to the discrepancy in $T_{B}$ signatures show in Figure 10. Comparing surveys 34 and 38 , it is suggested that lower frequencies show more sensitivity to surface roughness based on the deviation of 19 and $37 \mathrm{GHz} \mathrm{H}$-pol from $89 \mathrm{GHz} \mathrm{H}$-pol at higher incidence angles across the sediment-laden floe (Figure 10). Previous research has also indicated that horizontally polarized channels are more sensitive to surface roughness (Stroeve et al. 2006; Gupta and Barber 2015), which is in agreement with measured $T_{B}$ for survey 34 , as horizontally polarized channels show the most discrepancy between different surface roughness (Figure 11).

Future research in this field would benefit from discriminating the effects of widespread surface roughness versus liquid water presence on $T_{B}$.
Previous research on surface roughness and passive microwave signal has neglected to separate these two influences (Gupta and Barber 2015), a distinction that this research fails to make as well. Future research should focus on determining the frequency or polarization most sensitive to surface roughness in a controlled setting, where measurements can be made while surface liquid water is both absent and present. As well, a quantitative relationship between sediment concentration and melt rates can be derived in a controlled setting following methods outlined in this research. In combination this could provide a better understanding of how sediment influences surface deformation, and the resulting remotely detected sea ice concentration throughout the melt period.

\section{Significance}

To the authors' knowledge, previous literature does not exist examining the influence of sea ice surface sediment on passive microwave $T_{B}$. This is due to the fact that the spatial distribution of highly sedimentladen ice floes in the Arctic are regionally specific, restricted to shallow coastal regions where mechanisms of formation can occur (e.g., coastal Northern Alaska: Barnes et al. 1982; and Foxe Basin (Campbell and Collin 1958). Despite limitations to the conditions required for formation, previous studies have shown that during the summer, surface sediments can cover up to $50 \%$ in the Chukchi Sea (Tucker et al. 1999), and $10 \%$ in the Eurasian Sea (Pfirman et al. 1989). Insitu thermodynamic studies of these types of ice are rare, likely due to the restricted areas of sedimentladen ice development. As a result, it is currently unknown how dense surface sediment influences passive microwave $T_{B}$ under a variety of ice conditions.

This could lead to potential inaccuracies in remotely sensed sea ice concentration retrievals in coastal areas where this ice is concentrated. Inaccuracies in remotely sensed data reduces the reliability of earth process modeling, which is of importance in coastal regions in terms of processes such as sediment budgeting (Eicken et al. 2005; Huck et al. 2007; Wegner et al. 2017) and nutrient transport (Nomura et al. 2010). Accurate monitoring and modeling of these systems is becoming of increasing importance due to the current changing climate, driving rapid change in Arctic processes (Gagnon and Gough 2005). By improving satellite-based retrievals of sea ice concentrations, the accuracy of model predictions can be improved, enhancing our 
understanding of how earth system processes may change in response to our changing climate.

This paper contributes to this area by proposing the possible mechanisms through which sea ice surface sediment may influence the measured $T_{B}$ of the surface, and by exploring the details of one of these mechanisms. Results from this research provide merit for future research in this field, particularly on the precise influence of sediment on $\mathrm{T}_{B}$ throughout a gradient of sediment densities to provide accurate calibrations for sea ice concentration algorithms.

\section{Acknowledgments}

This project is part of the NSERC-Manitoba Hydro funded Collaborative Research and Development (CRD) program known as BaySys. Data collection for this research would not have been possible without the support and hospitality of the CCGS Amundsen crew during the 2018 field season. Canada Research Chair funding (DGB) and NSERC discovery grant funding (DGB and DI) supported research specific to this work, as did the University of Manitoba Graduate Fellowship (UMGF) and the Northern Scientific Training Program (NSTP). The authors would personally like to thank Laura Dalman and David Babb from the University of Manitoba (UofM) for assistance during physical ice sampling, Atreya Basu from the UofM for assistance with sediment grain size analysis, Wayne Chan from the UofM for statistical analysis assistance, and Cooper Harasyn from Queen's University during MATLAB script development. This work is a contribution to the ArcticNet Networks of Centres of Excellence and the Arctic Science Partnership (ASP, asp-net.org).

\section{Disclosure statement}

The authors declare that there is no conflict of interest regarding the publication of this manuscript.

\section{References}

Abraham, K. F., and Keddy, C. J. 2005. "The Hudson Bay Lowland." In The World's Largest Wetlands: Ecology and Conservation, edited by L. H. Fraser and P. A. Keddy, 118-142. Cambridge, UK: Cambridge University Press.

Andersen, S., Tonboe, R., Kaleschke, L., Heygster, G., and Pedersen, L.T. 2007. "Intercomparison of Passive Microwave Sea Ice Concentration Retrievals over the High-Concentration Arctic Sea Ice." Journal of Geophysical Research: Oceans, Vol. 112(No. 8): pp. 1-18. doi:10.1029/2006JC003543.

Andrews, J.S., Babb, D., and Barber, D.G. 2017. "Climate Change and Sea Ice: Shipping Acessibility on the Marine Transportation Corridor through Hudson Bay and Hudson Strait (1980-2014)." Elementa: Science of the Anthropocene is a Trans-Disciplinary, Vol. 5(No. 15). doi: 10.1525/elementa.130.
Asmus, K.W., and Grant, C. 1999. "Surface Based Radiometer (SBR) Data Acquisition System." International Journal of Remote Sensing, Vol. 20(No. 15-16): pp. 3125-3129. doi:10.1080/014311699211651.

Barber, D. G. 2005. "Microwave Remote Sensing, Sea Ice and Arctic Climate." Physics in Canada, Vol. 61: 105-111.

Barnes, P.W., Reimnitz, E.R.K., and Fox, D. 1982. "Ice Rafting of Fine-Grained Sediment, a Sorting and Transport Mechanism, Beaufort Sea, Alaska." Journal of Sedimentary Peterology, Vol. 52(No. 2): pp. 0493-0502.

Bergström, D. 2012. "Surface Generation and Analysis Matlab Code." MySimLabs, last modified Feb. 26 2012, mysimlabs.com.

Bernard, E., Friedt, J.M., Tolle, F., Griselin, M., Marlin, C.H., and Prokop, A. 2017. "Investigating Snowpack Volumes and Icing Dynmaics in the Moraine of an Arctic Catchment Using UAV Photogrammetry." The Photogrammetric Record, Vol. 32(No. 160): pp. 497-512. doi:10.1111/phor.12217.

Campbell, N.J., and Collin, A.E. 1958. "The Discoloration of Foxe Basin Ice." Journal of the Fisheries Research Board of Canada, Vol. 15(No. 6): pp. 1175-1188. doi:10.1139/ f58-062.

Carsey, F.D. 1985. "Summer Arctic Sea Ice Character From Satellite Microwave Data." Journal of Geophysical Research, Vol. 90(No. C3): pp. 5015-5034. doi:10.1029/ JC090iC03p05015.

Castro, S.L., Emery, W.J., Wick, G.A., and Tandy, W. Jr. 2017. "Submesoscale Sea Surface Temperature Variability from UAV and Satellite Measurements." Remote Sensing, Vol. 9(No. 1089): pp. 1-19. doi:10.3390/rs9111089.

Comiso, J.C., Grenfell, T.C., Bell, D.L., Lange, M.A., and Ackley, S.F. 1989. "Passive Microwave in Situ Observations of Winter Weddell Sea Ice." Journal of Geophysical Research, Vol. 94(No. C8): pp. 10891-10905. doi:10.1029/JC094iC08p10891.

Comiso, J.C., Meier, W.N., and Gersten, R. 2017. "Variability and Trends in the Arctic Sea Ice Cover: Results from Different Techniques." Journal of Geophysical Research: Oceans, Vol. 122(No. 8): pp. 6883-6900. doi:10.1002/2017JC012768.

Déry, S.J., Stieglitz, M., McKenna, E.C., and Wood, E.F. 2005. "Characteristics and Trends of River Discharge into Hudson, James, and Ungava Bays, 1964-2000.” Journal of Climate, Vol. 18(No. 14): pp. 2540-2557. doi:10.1175/ JCLI3440.1.

Du, J.Y., Kimball, J.S., Shi, J., Jones, L.A., Wu, S., Sun, R., and Yang, H. 2014. "Inter-Calibration of Satellite Passive Microwave Land Observations from AMSR-E and AMSR2 Using Overlapping FY3B-MWRI Sensor Measurements.” Remote Sensing, Vol. 6(No. 9): pp. 8594-8616. doi:10.3390/rs6098594.

Eicken, H., Gradinger, R., Gaylord, A., Mahoney, A., Rigor, I., and Melling, H. 2005. "Sediment Transport by Sea Ice in the Chukchi and Beaufort Seas: Increasing Importance Due to Changing Ice Conditions?" Deep-Sea Research Part II: Topical Studies in Oceanography, Vol. 52(No. 24-26): pp. 3281-3302. doi:10.1016/j.dsr2.2005.10.006.

Eppler, D. T., Farmer, L. D., Lohanick, A. W., Anderson, M. R., Cavalieri, D. J., Comiso, J. C., and Gloersen, P. 1992. "Passive Microwave Signatures of Sea Ice." In 
Microwave Remote Sensing of Sea Ice, edited by Frank D. Carsey, 47-71. Washington, DC: American Geophysical Union.

Gagnon, A.S., and Gough, W.A. 2005. "Trends in the Dates of Ice Freeze-up and Breakup over Hudson Bay, Canada." Arctic, Vol. 58(No. 4): pp. 370-382. doi: 10.1007/s10584-005-1815-8.

Garrity, C. 1992. "Characterization of Snow on Floating Ice and Case Studies of Brightness Temperature Changes During the Onset of Melt." In Microwave Remote Sensing of Sea Ice, edited by Frank D. Carsey. Washington, DC: American Geophysical Union.

Gentemann, C. L., Wentz, F. J., Brewer, M., Hilburn, K., and Smith, D. 2010. "Passive Microwave Remote Sensing of the Ocean: An Overview." In Oceanography from Space: Revisited, edited by Vittorio Barale, Jim F. R. Gower, and L. Alberotanza, 1-375. Berlin, Germany: Springer.

Grenfell, T.C., and Comiso, J.C. 1986. "Multifrequency Passive Microwave Observations of First-Year Sea Ice Grown in a Tank." IEEE Transactions on Geoscience and Remote Sensing, Vol. GE-24(No. 6): pp. 826-831. doi: 10.1109/TGRS.1986.289696.

Grenfell, T.C., and Lohanick, A.W. 1985. "Temporal Variations of the Microwave Signatures of Sea Ice During the Late Spring and Early Summer Near Mould Bay NWT." Journal of Geophysical Research, Vol. 90(No. C3): pp. 5063-5074. doi:10.1029/JC090iC03p05063.

Gupta, M., and Barber, D.G. 2015. "Sub-Pixel Evaluation of Sea Ice Roughness Using AMSR-E Data." International Journal of Remote Sensing, Vol. 36(No. 3): pp. 749-763. doi:10.1080/01431161.2014.1001081.

Hochheim, K.P., and Barber, D.G. 2014. "An Update on the Ice Climatology of the Hudson Bay System." Arctic, Antarctic, and Alpine Research, Vol. 46(No. 1): pp. 66-83. doi:10.1657/1938-4246-46.1.66.

Hofmann, M.A. 2015. "Searching for Effects in Big Data: Why p-Values Are Not Advised and What to Use Instead." Proceedings of the 2015 Winter Simulation Conference, Huntington Beach, CA, pp. 725-736.

Hong, S. 2010. "Detection of Small-Scale Roughness and Refractive Index of Sea Ice in Passive Satellite Microwave Remote Sensing." Remote Sensing of Environment, Vol. 114(No. 5): pp. 1136-1140. doi:10.1016/j.rse.2009.12.015.

Huck, P., Light, B., Eicken, H., and Haller, M. 2007. "Mapping Sediment-Laden Sea Ice in the Arctic Using AVHRR Remote-Sensing Data: Atmospheric Correction and Determination of Reflectances as a Function of Ice Type and Sediment Load." Remote Sensing of Environment, Vol. 107(No. 3): pp. 484-495. doi:10.1016/ j.rse.2006.10.002.

Ivanova, N., Pedersen, L.T., Tonboe, R.T., Kern, S., Heygster, G., Lavergne, T., Sørensen, A., et al. 2015. "Inter-Comparison and Evaluation of Sea Ice Algorithms: Towards Further Identification of Challenges and Optimal Approach Using Passive Microwave Observations." Cryosphere, Vol. 9(No. 5): pp. 1797-1817. doi:10.5194/tc-9-1797-2015.

Landy, J., Ehn, J., Shields, M., and Barber, D.G. 2014. "Surface and Melt Pond Evolution on Landfast First-Year Sea Ice in the Canadian Arctic Archipelago." Journal of
Geophysical Research: Oceans, Vol. 119(No. 5): pp. 2121-2128. doi:10.1002/jgrc.20224.

Larssen, B.B., Elverhøi, A., and Aagaard, P. 1987. "Study of Particulate Material in Sea Ice in the Fram Strait - a Contribution to Paleoclimatic Research?" Polar Research, Vol. 5(No. 3): pp. 313-315. doi:10.1111/j.1751-8369.1987. tb00561.x.

Lavergne, T., Sørensen, A.M., Kern, S., Tonboe, R., Notz, D., Aaboe, S., Bell, L., et al. 2019. "Version 2 of the EUMETSAT OSI SAF and ESA CCI Sea-Ice Concentration Climate Data Records." The Cryosphere, Vol. 13(No. 1): pp. 49-78. doi:10.5194/tc-13-49-2019.

Ledley, T.S., and Pfirman, S. 1997. "The Impact of Sediment-Laden Snow and Sea Ice in the Arctic on Climate." Climatic Change, Vol. 37(No. 4): pp. 641-664. doi:10.1023/A:1005354912379.

Light, B., Eicken, H., Maykut, G.A., and Grenfell, T.C. 1998. "The Effect of Included Particulates on the Spectral Albedo of Sea Ice." Journal of Geophysical Research: Oceans, Vol. 103(No. C12): pp. 27739-27752. doi: 10.1029/98JC02587.

Lohanick, A.W., and Grenfell, T.C. 1986. "Variations in Brightness Temperature over Cold First-Year Sea Ice near Tuktoyaktuk, Northwest Territories." Journal of Geophysical Research, Vol. 91(No. C4): pp. 5133-5144. doi:10.1029/JC091iC04p05133.

Markus, T., and Cavalieri, D.J. 2000. "An Enhancement of the NASA Team Sea Ice Algorithm.” IEEE Transactions on Geoscience and Remote Sensing, Vol. 38(No. 3): pp. 1387-1398. doi:10.1109/36.843033.

Nomura, D., Nishioka, J., Granskog, M.A., Krell, A., Matoba, S., Toyota, T., Hattori, H., and Shirasawa, K. 2010. "Nutrient Distributions Associated with Snow and Sediment-Laden Layers in Sea Ice of the Southern Sea of Okhotsk." Marine Chemistry, Vol. 119(No. 1-4): pp. 1-8. Elsevier B.V.: doi:10.1016/j.marchem.2009.11.005.

Onstott, R.G., Grenfell, T.C., Matzler, C., Luther, C.A., and Svendsen, E.A. 1987. "Evolution of Microwave Sea Ice Signatures during Early Summer and Midsummer in the Marginal Ice Zone." Journal of Geophysical Research, Vol. 92(No. C7): pp. 6825-6835. doi:10.1029/JC092iC07 p06825.

Peng, G., Meier, W.N., Scott, D.J., and Savoie, M.H. 2013. "A Long-Term and Reproducible Passive Microwave Sea Ice Concentration Data Record for Climate Studies and Monitoring." Earth System Science Data, Vol. 5(No. 2): pp. 311-318. doi:10.5194/essd-5-311-2013.

Pfirman, S., Gascard, J.-C., Wollenburg, I., Mudie, P., and Abelmann, A. 1989. "Particle-Laden Eurasian Arctic Sea Ice: Observations from July and August 1987.” Polar Research, Vol. 7(No. 1): pp. 59-66. doi:10.1111/j.17518369.1989.tb00604.x.

Reimnitz, E., Kempema, E.W., and Barnes, P.W. 1987. "Anchor Ice, Seabed Freezing, and Sediment Dynamics in Shallow Arctic Seas." Journal of Geophysical Research, Vol. 92(No. C13): pp. 14671-14678. doi:10.1029/ JC092iC13p14671.

Reimnitz, E., McCormick, M., McDougall, K., and Brouwers, E. 1993. "Sediment Export by Ice Rafting from a Coastal Polynya, Arctic Alaska, U.S.A.” Arctic and Alpine Research Arctic and Alpine Research, Vol. 25(No. 2): pp. 83-98. doi:10.2307/1551544. 
Ryan, J.C., Hubbard, A.L., Box, J.E., Todd, J., Christoffersen, P., Carr, J.R., Holt, T.O., and Snooke, N. 2015. "UAV Photogrammetry and Structure from Motion to Assess Calving Dynamics at Store Glacier, a Large Outlet Draining the Greenland Ice Sheet." Cryosphere, Vol. 9(No. 1): pp. 1-11. doi:10.5194/tc-9-1-2015.

Stroeve, J.C., Markus, T., Maslanik, J.A., Cavalieri, D.J., Gasiewski, A.J., Heinrichs, J.F., Holmgren, J., Perovich, D.K., and Sturm, M. 2006. "Impact of Surface Roughness on AMSR-E Sea Ice Products." IEEE Transactions on Geoscience and Remote Sensing, Vol. 44(No. 11): pp. 3103-3116. doi:10.1109/TGRS.2006.880619.

Tonboe, R.T., Eastwood, S., Lavergne, T., Sørensen, A.M., Rathmann, N., Dybkjaer, G., Pedersen, L.T., Høyer, J.L., and Kern, S. 2016. "The EUMETSAT Sea Ice Concentration Climate Data Record." The Cryosphere, Vol. 10(No. 5): pp. 2275-2290. doi:10.5194/tc-10-22752016.

Tucker, W.B., Gow, A.J., Meese, D.A., Bosworth, H.W., and Reimnitz, E. 1999. "Physical Characteristics of Summer
Sea Ice across the Arctic Ocean." Journal of Geophysical Research: Oceans, Vol. 104(No. C1): pp. 1489-1504. doi: 10.1029/98JC02607.

Ulaby, F. T., and Long, D. G. 2014. Microwave Radar and Radiometric Remote Sensing. London, UK: University of Michigan Press.

Ulaby, F. T., Moore, R. K., and Fung, A. K. 1986. Microwave Remote Sensing, Active and Passive, Volume III: From Theory to Applications. London, UK: University of Michigan Press.

Wegner, C., Wittbrodt, K., Hölemann, J.A., Janout, M.A., Krumpen, T., Selyuzhenok, V., Novikhin, A., et al. 2017. "Sediment Entrainment into Sea Ice and Transport in the Transpolar Drift: A Case Study from the Laptev Sea in Winter 2011/2012." Continental Shelf Research, Vol. 141(No. 1) Elsevier Ltd: pp. 1-10. doi:10.1016/ j.csr.2017.04.010.

Wentworth, C.K. 1922. "A Scale of Grade and Class Terms for Clastic Sediments." The Journal of Geology, Vol. 30(No. 5): pp. 377-392. doi:10.1086/622910. 